\title{
Review of Alzheimer's Disease: Treatments and New Pharmacological Strategies
}

\author{
Ara Santos Pérez \\ Department of Pharmacy, Universidad Europea de Madrid, Madrid, Spain \\ Email address: \\ arasantos@hotmail.es

\section{To cite this article:} \\ Ara Santos Pérez. Review of Alzheimer's Disease: Treatments and New Pharmacological Strategies. Pharmaceutical Science and \\ Technology. Vol. 3, No. 1, 2019, pp. 7-21. doi: 10.11648/j.pst.20190301.12
}

Received: April 26, 2019; Accepted: May 23, 2019; Published: June 13, 2019

\begin{abstract}
Alzheimer's disease belongs to a group of pathologies called dementias, being this one the most common type. It is a neurodegenerative disease that causes a progressive and disabling impairment of cognitive functions, including memory, comprehension, language, attention, reasoning and judgment. Until now there is no cure, although there are treatments available that can improve the symptoms. In this paper we describe the disease, its classification and prognosis, as well as its physio pathological mechanism and the different diagnostic techniques currently being used. In addition, we perform an analysis of different therapies both pharmacological and non-pharmacological, focusing on conventional drugs marketed so far, making a comparison between them, as well as those strategies or therapeutic targets that are being researched, different phases of clinical trials which project different perspectives towards the future. For this, we carry out a bibliographic review of the most updated scientific literature, analyzing the most relevant information about this disease. Unfortunately, in the last years there have not been relevant bibliography or studies done. Finally, as a practical contribution to complement and conclude this study, we collect the dispensing data of several pharmacy offices, in order to approximate the data obtained through the bibliographic analysis with the treatments that are currently used in the Spanish population. The data found coincide with the daily practice at the pharmacy: the population gets older and the most used drug is Donepezil.
\end{abstract}

Keywords: Alzheimer's Disease, Dementia, Pharmacological and Non-pharmacological Therapies, Dispensing Data

\section{Introduction}

Alzheimer's disease (AD) belongs to a group of pathologies generally referred to as dementias. This term does not refer to a specific disease, but generally implies a persistent and progressive decline in cognitive ability, serious enough to interfere with the activities of daily life. It is an acquired process, which differentiates dementias from mental retardation. [1-3]

$\mathrm{AD}$ is the most common type of dementia. It is a neurodegenerative disease that causes a progressive and disabling impairment of cognitive functions, including memory, comprehension, language, attention, reasoning and judgment. It appears normally at old age, being the beginning before 65 years (early onset) unusual (observed in less than $10 \%$ of patients with $\mathrm{AD}$ ). As it is a progressive disease, it entails a serious cognitive deterioration. There is no cure for $\mathrm{AD}$, although there are treatments available that can improve some symptoms. [1, 2]
The symptoms of $\mathrm{AD}$ depend on the stage in which the patient is. These stages are: preclinical, mild, moderate and delayed, depending on the degree of cognitive impairment. The symptom of initial presentation is usually the selective loss of short-term memory, followed by deterioration in problem solving, in judgment, in executive functioning, lack of motivation and disorganization. Next, there is language disorder and impairment of visuospatial skills. Neuropsychiatric symptoms such as apathy, social isolation, disinhibition, agitation, psychosis and wandering are also common in intermediate and late stages. At the end of the disease, there is difficulty in performing learned motor tasks (dyspraxia), olfactory dysfunction, sleep disturbances, extrapyramidal motor signs such as dystonia and Parkinsonian symptoms, followed finally by primitive reflexes, incontinence, inability to walk and swallow and total dependence of caregivers. All this inevitably leads to death, due to the appearance of multiple physical and mental complications, such as generalized rigidity. [1-3] 
Regarding its classification, two large groups of dementias are distinguished, according to their origin. [1]

On the one hand, the primary degenerative forms, of a progressive and irreversible nature, divided into:

a. Cortical: Alzheimer's disease, dementia due to Lewy bodies, fronto-temporal dementia.

b. Subcortical: dementias associated with Parkinson's disease, Huntington's chorea, spinocerebellar degeneration.

c. Other: dementias associated with multiple sclerosis, amyotrophic lateral sclerosis.

And, on the other hand, the secondary degenerative forms, some reversible, which can be vascular, hydrocephalic, traumatic, infectious, neoplastic [1]

\subsection{Physiopathological Mechanism of the Disease}

The selective loss of certain populations of neurons is a common occurrence of neurodegenerative diseases, to which the main clinical manifestations of each disease are attributed. The involvement of the entorhinal cortex, hippocampus and deep regions of the temporal lobe is the neuropathological substrate of recent memory loss in AD. [2]

The physio pathological mechanism of Alzheimer's is still unknown today. However, there are different alterations such as the presence and accumulation of abnormal neuritic plaques and neurofibrillary tangles, which are currently interpreted as residual structures of the disease, not as causal agents of degeneration. [3]

The plaques are microscopic, spherical lesions that have an extracellular amyloid beta peptide core surrounded by axonal terminations which are increased (Figure 1). This peptide is derived from a transmembrane protein called amyloid precursor protein (APP), and is cleaved from the APP by the action of the alpha, beta and gamma-secretase proteases. Generally, APP is divided by alpha or beta secretase and the small fragments that are formed, which are not toxic to neurons. However, when the sequential cleavage is performed by beta and gamma-secretase, amino acid peptides appear which are called beta-amyloid 40 and beta-amyloid 42. Elevations in the levels of beta-amyloid 42 (A $\beta 42)$ give rise to the aggregation of amyloid, which causes neuronal toxicity. [3]

The APP gene is located on chromosome 21, one of the regions related to $\mathrm{AD}$. Amyloid deposition in this disease occurs around the meningeal and cerebral vessels and the gray matter. These deposits of gray matter are multifocal, but they fuse to form miliar structures that are called plates.

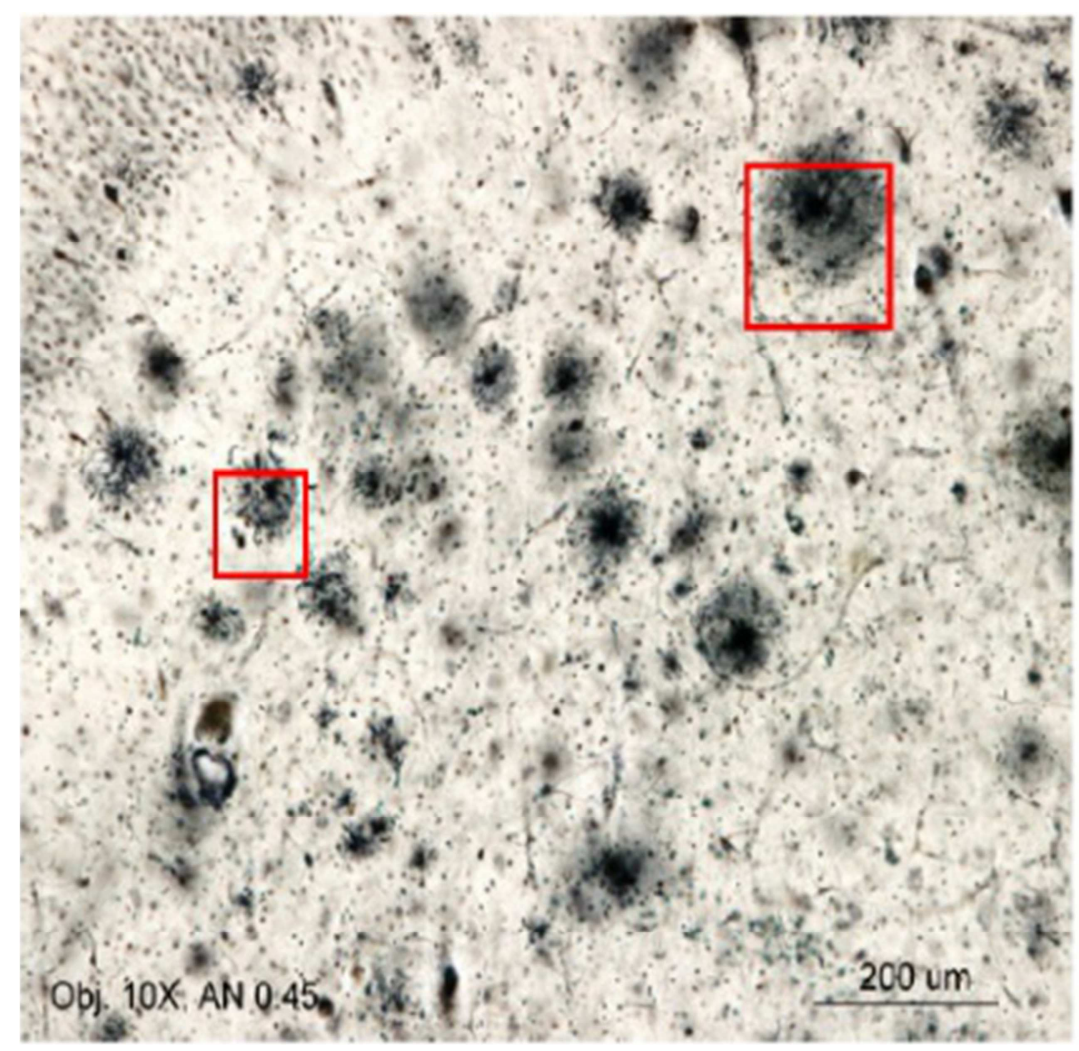

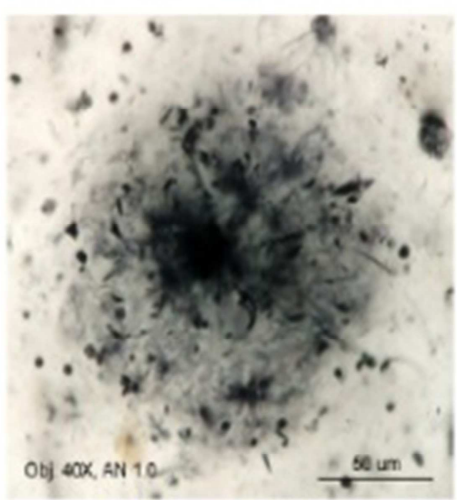

Placa clásica

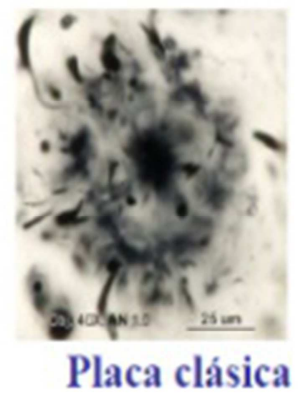

Figure 1. Images of different amyloid plaques obtained by the Bielschowsky method [4].

On the other hand, the neurofibrillary tangles (Figure 2) are fibrillar structures which are found inside the cytoplasm in neurons, formed by a protein called tau. [3]

The main function of this protein is to stabilize the axonal microtubules, which run along neuronal axons and are essential for intracellular transport. The set of microtubules is held together thanks to the tau protein. [3]

Due to the aggregation of extracellular beta-amyloid that 
occurs in $\mathrm{AD}$, there is a hyper phosphorylation of tau, which causes the formation of aggregates of this protein. The aggregates of tau form twisted, matched helical filaments that are known as neurofibrillary tangles. They occur first in the hippocampus and can then be seen throughout the cerebral cortex. [3]
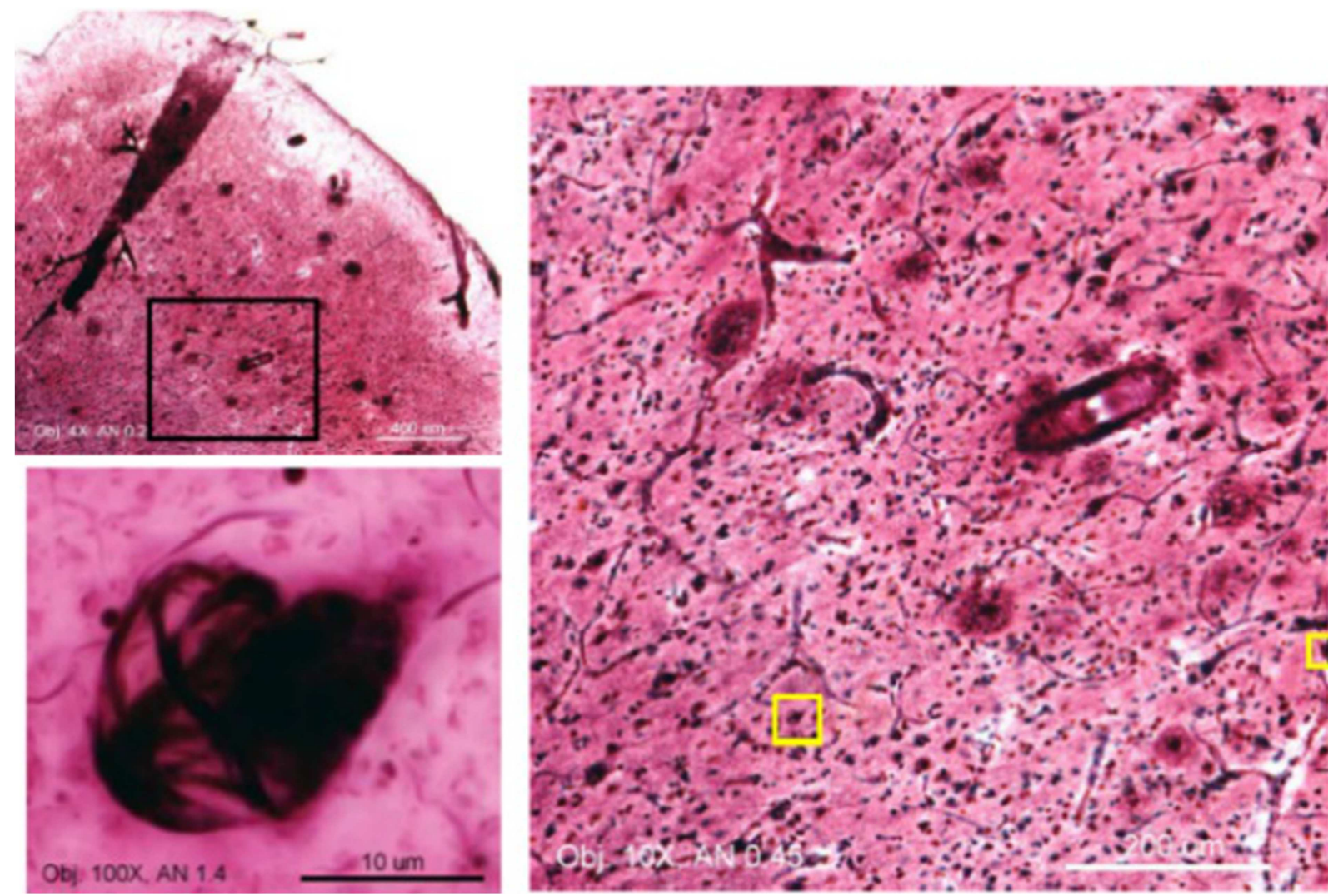

Figure 2. Images of neurofibrillary tangles obtained by the ammoniacal silver oxide method [4].

Another feature of $\mathrm{AD}$ is the granulovacuolar degeneration of pyramidal cells of the hippocampus due to amyloid angiopathy. [3]

\subsection{Diagnostic Techniques}

The early diagnosis of $\mathrm{AD}$ through the use of biomarkers could facilitate the implementation and monitoring of early therapeutic interventions with potential capacity to significantly modify the course of the disease. The diagnosis in the preclinical phase and the therapeutic intervention in this phase, are therefore key points to slow down the progression of the disease. $[5,6]$

There are several biomarkers that seem to be able to identify individuals with the disease in preclinical phase, and can predict their development in the future. These are found in the cerebrospinal fluid (CSF) and they are the $\beta$-amyloid peptide 42 , the tau protein and the phosphorylated tau protein (P-tau). [6]

Although the sensitivity is very high, there are problems regarding the specificity of the combination of these complementary biomarkers, since the appearance of these levels of proteins in the cerebrospinal fluid is not exclusive of $\mathrm{AD}$, and may be altered in other neurodegenerative diseases causing of dementia, such as frontotemporal dementia with Parkinsonism, corticobasal degeneration, progressive supranuclear palsy, Down syndrome and Pick's disease, where the metabolism of the misfolded and hyper phosphorylated tau protein is also altered. These are the socalled tauopathies. [8]

The accumulation of $\beta$-amyloid $42(\mathrm{~A} \beta 42)$ in the CSF of patients with probable diagnosis of $\mathrm{AD}$ was also associated with controls. This accumulation seems to affect various aspects of the physiological functions of the cells. It has been demonstrated the existence of an inverse correlation between the number of senile plaques in autopsy with CSF obtained intraventricularly, and those obtained in CSF obtained by ante-mortem lumbar puncture, and also between the amyloid load by amyloid radio ligand (amyloid PET) with that of $\mathrm{A} \beta 42$ in the LCR. However, the decrease of $A \beta 42$ in the CSF is also observed in other processes with no apparent relationship with the formation of senile plaques, such as severe head trauma, systemic lupus erythematosus, use of certain anesthetics, dementia associated with the immunodeficiency virus human, multisystemic atrophy, amyloid angiopathies and subcortical vascular leukoencephalopathy. [1,9]

It has not been assigned any clear pattern of superiority to a particular CSF or combination of CFS, although the levels of sensitivity and specificity achieved are greater than $80 \%$ when comparing the results between patients with $\mathrm{AD}$ and healthy patients or controls without any type of dementia. Nevertheless, there is sufficient evidence to show that the 
decrease in $\beta$-amyloid levels and the increase in tau and / or P-tau levels constitute a specific feature of Alzheimer-type pathology. $[1,10]$

The biomarkers of CSF have been used to increase the evidence of the underlying pathology of $\mathrm{AD}$ in mild cognitive impairment. [11]

Since classification based on CSF biomarkers is often contradictory, it has been shown that normalization of the $\mathrm{A} \beta 42$ concentration to the level of total amyloid beta $(A \beta)$, using the $A \beta 42 / 40$ ratio, improves the distinction between $\mathrm{AD}$ and dementia no $\mathrm{AD}$. There is a study where it was evaluated whether this relationship would improve the categorization of mild cognitive impairment and would predict with more precision the progression of the disease. The results were positive. [11]

There is then a great interest in obtaining image markers (Computed Axial Tomography (CT), Nuclear Magnetic Resonance (NMR), and others) or biochemical (from body fluids, such as blood or cerebrospinal fluid) that do not depend on fundamentally subjective interpretations and that allow to identify the beginning or the degree of evolution of the disease. This would facilitate the development of new preventive or curative treatments. $[1,12]$

The classic biomarkers of CSF and the approved structural and functional neuroimaging have a limited clinical application given their invasive nature and / or their high cost. However, blood biomarkers are affordable and effective over time with respect to the previous ones. However, the immediate applicability of blood biochemical biomarkers in clinical practice is not very likely. The main limitations come from the difficulties to measure and standardize the thresholds between the different laboratories. [5]

It is worth highlighting a study conducted in 2012 where 128 patients underwent clinical and cognitive evaluations, brain images and biochemical analyses of CSF and blood. All of them had a close relationship with the hereditary EA. Participants at risk of carrying a mutation for autosomal dominant AD were enrolled and completed assessments over 2 years. The results showed that the concentrations of $\beta$ amyloid in CSF begin to decrease 25 years before the onset of clinical symptoms. [13]

In addition, decreased concentrations of $\beta$-amyloid measured by Individual Photon Emission Computed Tomography (SPECT) were detected 15 years before the onset of clinical symptoms. The increase in tau protein concentrations in the CSF and the increase in brain atrophy were also detected 15 years before the onset of symptoms. A reduction in cerebral metabolism and a deterioration of episodic memory was observed 10 years before the appearance of clinical symptoms characteristic of the disease. Finally, with 5 years of advance, cognitive global alterations could be registered thanks to the Mini Mental State Examination (MMSE) and the Clinical Dementia Rating Scale. All this indicates that the AD process begins more than 20 years before the clinical appearance of dementia. Clinical studies on treatment and prevention could incorporate these biomarkers to measure the probability of clinical success in the future. $[1,2]$

The MMSE test is a quick test, easy to interpret with a version validated in Spanish, through which aspects of the cognitive sphere such as memory, orientation, language, skills or attention are evaluated. It takes about 10 minutes for its realization and assessment. The test can reach a maximum score of 30 points, the ranges that are considered normal are between 25 and 30 points, while a score of 24 or fewer points suggests that the person could have some type of cognitive impairment. This deterioration in Alzheimer's patients is progressing, with an average decrease of 3 points per year. $[1,2,14]$

Hereditary forms of $\mathrm{AD}$ are very rare (around $1 \%$ of all cases) and genetic mutations, currently known, do not have a single determining factor, so no genetic study is routinely indicated in patients with clinical dementia. $[1,2,14]$

Imaging tests have therefore acquired a high diagnostic value for patients with dementia.

Brain NMR is able to detect vascular changes and allows the exclusion of other brain pathologies that is the reason why it is considered one of the imaging tests of choice when making a definitive diagnosis of AD. [12]

The cranial $\mathrm{CT}$ is an alternative to NMR that allows to demonstrate a possible ventricular dilation and increase of the cortical grooves. In addition, SPECT can be useful in the differential diagnosis of the type of dementia. [12]

And, finally, the image test most recently used in the clinic consists of obtaining images using Positron Emission Tomography (PET), which allows the determination of the density of neuritic plaque of $\beta$-amyloid in the brain of adult patients with deterioration that are being evaluated for $\mathrm{AD}$ and other causes of cognitive impairment. [12]

Florbetapir ${ }^{\circledR}$ is a licensed radiopharmaceutical for PET imaging of the neuritic plaque density of $\beta$-amyloid in the brain of adult patients with cognitive impairment who are being evaluated for $\mathrm{AD}$ and other causes of cognitive impairment. [12]

This test has a sensitivity value of $92 \%$, which means that it is able to detect at least $92 \%$ of the subjects who present relevant amounts of $\beta$-amyloid plaques in the cerebral cortex. In addition, it has a sensitivity of $100 \%$, that is, it is able to exclude healthy subjects from false positives, providing a high degree of safety in the differential diagnosis. [12]

Other subsequent clinical studies carried out in 2012, support these results. This drug has a good tolerability, with few adverse effects, in addition to showing high radioactive safety, both for the patient and for the health personnel involved in the administration of this type of radiopharmaceuticals. [15-17]

However, the presence of $\beta$-amyloid plaques does not indicate a definitive diagnosis of $\mathrm{AD}$, since these plaques may be present in patients with other neurological disorders, or even in elderly people without cognitive impairment. However, the absence of these plaques can rule out the possibility of suffering from $\mathrm{AD}$, which is very useful in the differential diagnosis. [12] 


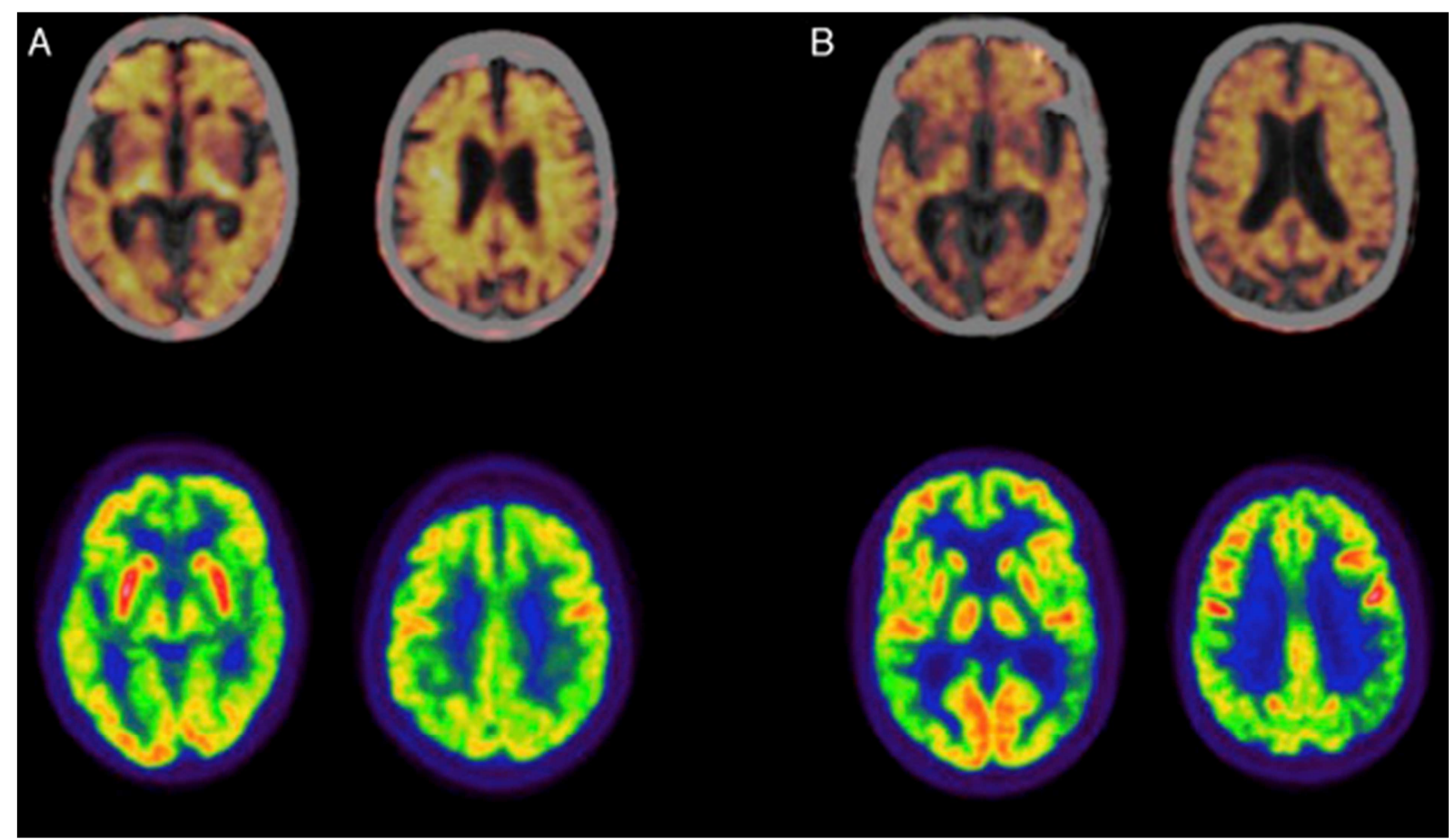

Figure 3. Studies of PET with florbetapir and 18F-Fluorodeoxyglucose in patients diagnosed with Alzheimer's disease.

A) A 79-year-old woman with a diagnosis of typical Alzheimer's disease. PET with florbetapir is positive for the presence of cortical amyloid plaques. B) A 57-year-old male patient diagnosed with Alzheimer's disease with predominant language involvement. PET with florbetapir is positive for the presence of cortical amyloid plaques. [12].

\subsection{Patient Classification}

$\mathrm{AD}$ is typical of advanced ages of life, although there may rarely be early forms that begin between 50 and 60 years or even earlier. It is invariably a progressive disease. The average life expectancy for a person aged 65 or older diagnosed with this disease is approximately 4 to 8 years, although some people with $\mathrm{AD}$ can live up to 20 years after the first signs of the disease. It ends with the death of the patient, with pneumonia being the most common cause. [3]

Within the $\mathrm{AD}$, there is a classification where different stages are differentiated:

a. Preclinical phase.

At this stage, patients present a mild memory loss without significant functional impairment in their daily activities. It is classified as mild cognitive impairment. These first pathological changes begin in the entorhinal cortex, followed by the hippocampus. [1,3]

b. Mild Alzheimer's disease.

Cognitive impairment begins at this stage as the disease progresses to the cerebral cortex, and usually lasts about two years. Along with memory loss, there is an inability to remember new information, things and appointments are forgotten. Other symptoms are repetitive questions and conversations, confusion, disorientation, personality changes, mood swings, loss of spontaneity and deterioration in reasoning and judgment. $[1,3]$

c. Moderate Alzheimer's disease.

This stage usually develops for 3-5 years. The disease spreads to more areas of the cerebral cortex responsible for language, reasoning and sensory processing. There is more loss of memory and attention, and begins to appear behavioural problems such as walking and agitation. Patients at this stage have trouble recognizing their own family and friends. They have apathy, social withdrawal and loss of inhibition. They often make repetitive statements and lose control of impulses. They also have difficulty with language, reading and writing. $[1,3]$

d. Severe Alzheimer's disease.

The disease progresses to extend throughout the cortex in the later stages. Patients in this phase of AD completely depend on others for daily activities. In addition, they become incontinent in the bladder and bowel and may have difficulty swallowing (dysphagia), there are risks of pneumonia, dehydration and malnutrition. Patients usually remain in bed or bedridden, and death usually occurs due to pneumonia or other breakthrough infection. $[1,3]$

\subsection{Prognosis}

The global prevalence of $\mathrm{AD}$ is up to 24 million and is projected to increase 4 times by 2050. The age-specific incidence increases significantly, from less than $1 \%$ per year before age 65 to $6 \%$ per year after 85 years of age. The incidence rates of $\mathrm{AD}$ are slightly higher for women, especially after 85 years of age. [3]

The risk factors of dementias are divided into nonmodifiable and potentially modifiable.

Among the non-modifiable risk factors are age, female sex 
and the genetic background related to the disease. Several studies relate the female sex with a higher risk of developing $\mathrm{AD}$, especially after 85 years of age. In addition, first-degree relatives of patients with $\mathrm{AD}$ have between 10 and $30 \%$ more likely to develop this condition. The EA of genetic origin represents only $0.5-1 \%$ of all cases. $[18,19]$

Potentially modifiable factors, also known as non-genetic risk factors, may be vascular risk factors, arterial hypertension (HT), hypercholesterolaemia, diabetes mellitus and smoking, among others. [1,2]

A meta-analysis carried out by Zhong's group in 2015 showed that active smokers show, compared to non-smokers, a $30 \%$ increase in the risk of suffering from any type of dementia: $40 \%$ for $\mathrm{AD}$ and $38 \%$ for vascular dementia. On the contrary, quitting smoking decreases the risk of suffering from some type of dementia. [20]

Data from the Kungsholmen project, a Swedish population study, showed that both a high systolic blood pressure (BP) $(>180 \mathrm{mmHg})$ and a systolic BP $<140 \mathrm{mmHg}$ are associated with an increased risk of AD and dementia in general. This association may vary depending on the age. [21]

There are other biological factors such as hyperthyroidism, depression and levels of hormones in the blood that alter the risk of developing AD. [2]

It has also been proven that certain lifestyle habits or food intake can reduce the occurrence of AD. In this way, biological and epidemiological studies suggest that the reduced intake of omega-3 polyunsaturated fatty acids is associated with an increased risk of dementia. In addition, another longitudinal study suggests that the Mediterranean diet and fish consumption are associated with a reduction in the risk of $\mathrm{AD}$ and dementia in general. [2]

The justification is based on the potential effects that these substances have on the development of brain neurons, in addition to their protective antioxidant effect on cell membranes and the possible neurochemical mechanisms related to Alzheimer's disease, such as the inverse relationship that has been determined between the blood levels of $\beta$-amyloid and the content of omega- 3 fatty acids in the diet. [2]

\section{Method}

A bibliographic review of the scientific publications available on the internet concerning Alzheimer's disease has been carried out: physio-pathological mechanism, diagnostic techniques, classifications, prognosis, commercialized treatments and treatments under study.

For this, the databases of PubMed (the base of scientific articles associated with MedLine) and Google Scholar have been consulted. In addition, the website of the Spanish Agency of Medicines and Medical Devices (AEMPS) was consulted to access the technical specifications of different drugs. Through these links sites, the articles used as bibliographic references were identified and selected.

The keywords that were used in the search were Alzheimer's, Alzheimer's disease, Alzheimer's treatment, biomarkers of Alzheimer's, Alzheimer's immunotherapy, and the different treatments and existing therapeutic strategies to make a more specific search. In addition, their equivalents in English were used.

The criteria for selection and inclusion of the different articles were: the content relevant to the objectives of this review and a maximum age of 10 years, with preference for those articles from prestigious scientific journals and with all the necessary bibliographic data.

The year of publication and the quality of the scientific articles were established as exclusion criteria. After the initial preselection of documents, we proceeded to the more detailed reading of the respective summaries. In this way, it was possible to discard those articles with outdated information, redundant or of little interest, articles repeated in different journals or databases, and those whose approaches did not adjust adequately to the needs of the research.

Finally, a total of 51 bibliographical references cited throughout the work in its entirety have been selected.

On the other hand, the data of the dispensations of the treatments commercialized for the $\mathrm{AD}$ in the last 12 months of 2017 were collected, and a graphic was elaborated to reflect them. For this, two pharmacy offices were chosen (Pharmacy I and Pharmacy II), both in two differentiated neighborhoods, with different types of population: Pharmacy I presents a mainly young population, newly established families that are gradually incorporating their relatives of older age to the family nucleus. Pharmacy II, on the other hand, belongs to a neighborhood of older population. The data is collected in both cases, directly from the software commonly used (UNICOP) avoiding the subjectivity of the number of patients treated, we will always refer to the number of units dispensed.

\section{Results and Discussion}

There are positive results of the treatments that are currently being carried out, although there is no curative treatment until now for primary degenerative dementias, including $\mathrm{AD}$. The evolution of the disease cannot be stopped, although there are some treatments that are beginning to show a slight retarding effect of this evolution. [3]

In addition to slowing down the progression of cognitive decline, the general objectives of dementia treatment are to adequately control psychological symptoms such as anxiety, depression or psychosis, which often appear at intermediate or advanced stages of the disease, and prevent or control the associated pathologies, delay the loss of functional capacity of the patient as much as possible and, to the same extent, perform an active support to the caregiver. [1, 3]

For this, environmental and behavioural approaches are especially beneficial in the management of behavior problems. Simple approaches, such as maintaining a family environment, controlling personal comfort, providing safety objects, redirecting attention and avoiding confrontation, can be very useful in managing behavior problems. [1, 3] 
Therefore, there are two complementary types of interventions: pharmacological and non-pharmacological.

The main symptom of this pathology is an alteration of memory, so it is thought that maybe there is a defect around cholinergic function, specifically in the synthesis or degradation of acetylcholine. Acetylcholine is a chemical used by nerve cells to communicate with each other and it is important for learning, memory and cognitive functions. The physiological anomalies observed in $\mathrm{AD}$ are related to the transport of choline and the release of acetylcholine, among others. [22]

Cholinesterase inhibitors (ChEIs) act increasing the level of this chemical and thus improving cognitive deficits. At the end of the nineties, three drugs of this category were introduced into therapeutics for the symptomatic treatment of $\mathrm{AD}$ : donepezil, rivastigmine and galantamine, which were approved by the Federal Drugs Administration (FDA) for the treatment of AD. [3]

On the other hand, glutamatergic hyperfunction that compensates for cholinergic hypofunction leads to a toxic effect for nervous tissue. The use of glutamic acid receptor antagonists is also approved by the FDA to treat moderate to severe AD. It can be administered in combination with ChEIs. [3]

\subsection{Non-pharmacological Treatments}

Some cases of AD may be due to potentially modifiable risk factors. Its incidence could be reduced through better access to education and the use of effective methods aimed at reducing the prevalence of vascular risk factors (for example, physical inactivity, smoking, hypertension during middle age, obesity of the middle age and diabetes) and depression. [1]

Non-pharmacological interventions are those therapeutic approaches that do not resort to drugs, but through interventions by professionals (speech therapists, psychologists...) are aimed at stimulating and maintaining mental abilities, avoiding the disconnection of the environment and strengthening social relationships, preventing and improving behavioural disorders. They increase the patient's personal autonomy, stimulate their own identity and self-esteem, minimize stress and avoid anomalous psychological reactions, always using those functions that are still active and, in this way, improve the quality of life of the patient and their relatives and / or caregivers. The use of these non-pharmacological therapies delays the entry of the patient in a residence, from several months to several years. [1, 23]

We can remark diverse forms or techniques of psychotherapy, which are carried out by qualified professionals and specialized in this type of patients. In reality, orientation therapy is the most used form of treatment. It consists of providing updated and real information of the patient's environment, to guide him in space, time and in his own identity. It is done in a group, together with other patients with mild and moderate dementia. [1]

On the other hand, reminiscence techniques aim to evoke memories of each patient's past to maintain their own identity and improve their self-esteem. This technique is also indicated in mild and moderate stages. [1]

Sensory stimulation avoids monotonous environments through the provocation of sensations, which include music therapy, plastic arts. [1]

Validation therapy reinforces the patient's thinking, even if it is wrong. It consists of repeating what the patient says, making positive reminiscences, relating their behavior to an unmet need and using ambiguity in the answers. [1]

In addition, rehabilitation and cognitive training enhance the preserved aspects of the patient's mind through the repetition of standardized activities, working on specific functions (attention, memory, and others). In recent years some computer programs have been created aimed at the cognitive stimulation of dementias by computer. Some of these programs used are RehaCom or the Smartbrain. [24, 25]

The patient's environment is changed or adapted to favour its temporo-spatial orientation, thus facilitating the development and collaboration in psychotherapeutic techniques. [1]

It is necessary to mark stable routines, signal the rooms of the house or the contents of the cabinets with written posters or photos (depending on the degree of dementia), create a pleasant atmosphere suppressing annoying noises, with adequate lighting and avoid overloaded environments.

It is advised that patients maintain their own autonomy whenever possible, using the necessary technical aids (grooming, when dressing...). [1]

Physical activity and daily walks slow down the alteration of the circadian rhythm and physical exercise improves coordination, mood, insomnia and social relationships. There is a recent meta-analysis conducted in 2016 with 802 patients, which shows that physical activity interventions positively influence cognitive function in patients with dementia. In addition, it is found that this beneficial effect is totally independent of the clinical diagnosis and the frequency of the intervention, and it is linked to actions that included aerobic exercises. $[1,26]$

As for food, food should be attractive in case of lack of appetite, and easy to swallow. It is essential to maintain good hydration and, occasionally, protein supplements are required. In the most advanced stages of the disease, the appearance of dysphagia (inability to swallow) is typical, so the use of thickeners is recommended. Weight loss is associated with a progression of AD. [1]

The caregiver is the person who assumes responsibility for the care, support and daily care of any type of sick person. He or she accompanies the patient most of the time. [1]

$\mathrm{He}$ or she is trained to communicate with the patient according to the degree of dementia. Caregivers should speak slowly, using short and simple sentences, avoiding questions with several options and always combining verbal and nonverbal communication. The visual and physical contact is important.

The family is in $94 \%$ of the cases responsible for the care 
of the person with $\mathrm{AD}$. [1]

\subsection{Pharmacological Treatments}

For years, numerous clinical trials have been conducted in humans with different molecules for the treatment of $\mathrm{AD}$, but none have reached the positive results required by the Health Authorities for commercialization and clinical use. [27]

In addition, clinical trials with drugs in dementia and, in particular, in $\mathrm{AD}$ are subjected to a large number of difficulties. The age of the patients susceptible to benefit from the therapeutic effects that these medicines can provide them, is one of them. Due to the advanced age of people suffering from this type of pathologies, participation in trials is lower, especially in the case of new medicines. [1]

For this reason, from the pharmacological treatments for $\mathrm{AD}$ commercialized until now only four drugs remain, which are properly grouped into two therapeutic groups: ChEIs and Glutamatergic Antagonists.

Each one has a different effect depending on the stage of the disease (mild, moderate or severe) and according to the manifestations of AD. [27]

ChEIs improves cholinergic transmission (principally involved in memory and learning) through the inhibition of the enzyme acetylcholinesterase (cholinesterase predominant in the brain) reversibly but lasting (between 30 minutes and 6 hours). The drugs currently used are donepezil, rivastigmine and galantamine, which bind to the enzyme through a covalent bond that they form with the active site of the enzyme. [1]

a. Donepezil (Aricept ${ }^{\circledR}$, Lixben $\AA$, Yasnal ${ }^{\circledR}$ and GSP).

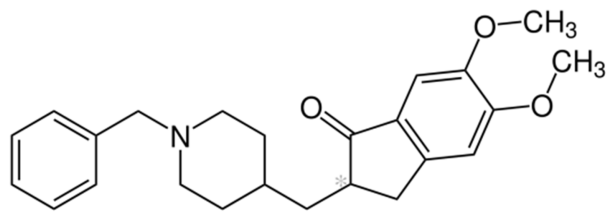

Figure 4. Chemical structure of Donepezil.

Donepezil is a specific and reversible inhibitor of acetylcholinesterase that is indicated for the symptomatic treatment of mild to moderately severe $\mathrm{AD}$, and acts non competitively.

In patients suffering from the disease (adults/elderly patients), treatment starts with $5 \mathrm{mg} /$ day. The tablets are administered orally at night, just before bedtime. This dose should be maintained for at least one month, in order to evaluate the first clinical responses to treatment and allow the steady state concentrations of donepezil hydrochloride to be achieved. After the first month and after evaluating the response to treatment, the dose can be increased to 10 $\mathrm{mg}$ /day, maximum recommended daily dose. Doses greater than this have not been studied in clinical trials.

Treatment with donepezil should only be started if a caregiver is available, which controls the taking of the drug by the patient, and whenever there is a therapeutic benefit it can be continued, which means that it must be re-evaluated on a regular basis.
However, the use of Donepezil in patients with severe Alzheimer's dementia, with other types of dementia, or with other types of memory impairment has not been investigated.

The most frequent adverse reactions are diarrhea, muscle cramps, headache, fatigue, nausea, vomiting and insomnia. [28]

b. Rivastigmine $\quad($ Exelon $\AA, \quad$ Prometax $\AA, \quad$ Demelora $\AA$, Nimvastid ${ }^{\circledR}$ and GSP).<smiles>CCN(C)C(=O)Oc1cccc([C@@H](C)N(C)C)c1</smiles>

Figure 5. Chemical structure of Rivastigmine.

Rivastigmine is another specific and reversible inhibitor of acetylcholinesterase and butyrylcholinesterase, which is also indicated for the symptomatic treatment of mild to moderately severe $\mathrm{AD}$, and it is also used as a treatment for Parkinson's. It acts in a competitive way

Therapy, as with donepezil, should only be initiated if a caregiver is available to regularly monitor the dose of the drug.

The initial dose is $1.5 / 2 \mathrm{mg}$ twice a day. If this dose is tolerated correctly after at least two weeks, it can be increased to $3 \mathrm{mg}$ twice a day. Subsequent increases of 4.5 and $6 \mathrm{mg}$ twice daily should be based on the good tolerability of the previously administered dose.

The effective dose is 3 to $6 \mathrm{mg}$ twice a day, and the maximum recommended daily dose is $6 \mathrm{mg}$ twice a day. Treatment can be continued whenever there is a therapeutic benefit for the patient, so it is re-evaluated periodically, especially in patients treated with doses less than $3 \mathrm{mg}$ twice a day. If after 3 months of treatment with maintenance dose no improvement is recognized, the treatment is interrupted.

Rivastigmine is contraindicated in patients with hypersensitivity to the active substance, other derivatives of the carbamate or to any of the excipients, in addition to those who suffer severe hepatic insufficiency, since it has not been studied in this population group.

The most common adverse reactions are gastrointestinal reactions that include nausea and vomiting, especially during the dose determination phase. [29]

c. Galantamine (Reminyl ${ }^{\circledR}$, Galnora ${ }^{\circledR}$ and GSP).

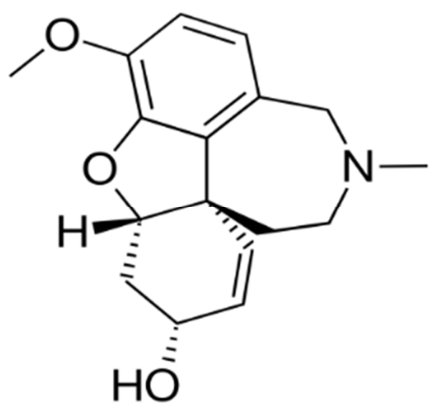

Figure 6. Chemical structure of Galantamine. 
Galantamine is the third specific and reversible inhibitor of acetylcholinesterase indicated for the symptomatic treatment of mild to moderately severe AD and Parkinson's. It also acts competitively.

The recommended initial dose is $8 \mathrm{mg}$ /day for 4 weeks. The tolerance and dosage of galantamine should also be reassessed regularly, preferably 3 months after starting treatment. As with the other two ChEIs drugs used to treat $\mathrm{AD}$, treatment with galantamine may be continued as long as there is a favourable therapeutic benefit and the patient can tolerate treatment with galantamine. Otherwise, the interruption of the treatment with said drug should be assessed. There is no rebound effect after the abrupt suspension of the treatment.

The initial maintenance dose is $16 \mathrm{mg}$ /day for at least 4 weeks. The dose increase to $24 \mathrm{mg} /$ day should be done individually, after an adequate assessment of both clinical benefit and tolerability.

Due to the lack of data on the use of galantamine in patients with significant renal and hepatic insufficiency, the use of this drug is contraindicated in such patients.

The most frequent adverse reactions are nausea and vomiting, as with other ChEIs drugs. [30]

d. Memantine (Exura ${ }^{\circledR}$, Ebixa ${ }^{\circledR}$, Mantinex $\AA$, Marixino ${ }^{\circledR}$, Protalon ${ }^{\circledR}$ and GSP).

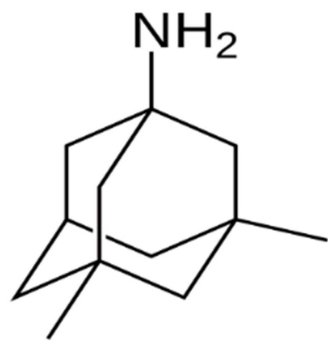

Figure 7. Chemical structure of Memantine.

Memantine is a non-competitive glutameric antagonist of moderate affinity, which modulates the effect of the pathological elevation of the glutamate tonic levels, which can cause neuronal dysfunction. It is indicated in the treatment of patients with moderate to severe AD.

Like the other treatments indicated for this pathology, the importance of the existence of a caregiver is essential to initiate treatment with memantine.

Tolerance and memantine dosage should be evaluated regularly, preferably during the three months following the start of treatment. From that moment, the clinical benefit of memantine and the tolerance of the treatment by the patient will be observed to know if they are favourable and should continue as before, on the contrary, the interruption will proceed, in case that its therapeutic effect is not evidenced or if the patient does not tolerate the treatment.

The initial dose is $5 \mathrm{mg}$, and the maximum daily dose is 20 $\mathrm{mg}$ once a day. To reduce the risk of adverse reactions, the maintenance dose is reached by increasing the dose $5 \mathrm{mg}$ every week for the first 3 weeks.

It is contraindicated in patients with epilepsy, a history of seizures or with factors that predispose to epilepsy.

The most frequent adverse reactions are dizziness, headache, constipation, drowsiness and hypertension. [31]

It is known that these four described drugs are commonly used in the treatment of dementia. In routine clinical practice, dementia is often monitored through the MMSE. A study carried out in 2018 conducted a systematic review and a meta-analysis of the effects of these drugs on MMSE scores through eighty trials. After 6 months, the estimates of the pooled effects were favourable for both ChEIs and memantine. [32]

However, not all existing ChEIs are currently commercialized. Tacrine (THA) was the first clinically effective acetylcholinesterase inhibitor, and the first drug approved for the treatment of $\mathrm{AD}$, but was withdrawn from the market due to its side effects, in particular due to its hepatotoxicity. [33]

\subsection{Comparative Between the Different Conventional Treatments}

Donepezil is the most commonly used drug for the treatment of AD. A study was carried out in which the effects of this drug on the cognitive functions and the expression levels of $\beta$-amyloid $(A \beta)$ in the peripheral blood of patients suffering from the disease were examined. In total, 76 patients visited the Department of Neurology of the Binzhou City Center Hospital from June 2015 to September 2016, which experienced a decrease in memory for more than three consecutive months and were submitted to the MMSE. The total number of patients was divided randomly into two groups: experimental group $(\mathrm{n}=38)$ and control group $(\mathrm{n}=$ 38). Patients in the control group were treated with conventional medications combined with Nimotop (solution for perfusion indicated for the prevention of neurological deterioration caused by cerebral vasospasm secondary to subarachnoid hemorrhage due to rupture of the aneurysm) and patients in the experimental group received combined conventional pharmacological therapy with donepezil, and the results of the treatment were compared in the two groups. The scores of both the MMSE and the Montreal Cognitive Assessment (MoCA), which is another short screening test that assesses the general cognitive status alternative to the traditional MMSE, were observed. The pharmacological therapy combined with donepezil is related to the scores of both tests of patients with $\mathrm{AD}$, which can decrease the level of $\mathrm{A} \beta$ in peripheral blood and improve the cognitive functions of patients, thus having important clinical importance. [34]

On the other hand, it is known that weight loss accelerates cognitive deterioration and increases mortality in patients with dementia. ChEIs causes loss of appetite, but sometimes in certain patients the change from donepezil to rivastigmine improves appetite. This is because butyrylcholinesterase inactivates ghrelin, which is an orexigenic hormone that regulates feeding and weight control.

A study was conducted during 6 months where the subjects were patients with mild to moderate $\mathrm{AD}$ treated half with 
rivastigmine patches and the other half with donepezil. Before and after the treatment, appetite, cognitive function and blood biochemical variables were evaluated, including several hormones. The results revealed that treatment with rivastigmine significantly improved appetite, while treatment with donepezil did not. In addition, rivastigmine significantly decreased the activity of serum cholinesterase and increased the level of cortisol. [35]

\subsection{New Therapeutic Targets and Pharmacological Strategies}

The number of approved drugs for the clinical treatment of $\mathrm{AD}$ remains limited. For this reason, there is an extensive search for new therapies. The ChEIs have proven benefits in slowing the progression of the disease and, therefore, are the first-line therapeutic approach. [36]

There are two ChEIs drugs that have not yet been commercialized: Huperizine A, which is a plant extract that shows a high and selective inhibition of central cholinesterases, and Latrepirdine (Dimebon ${ }^{\circledR}$ ), a drug approved in some countries as a broad spectrum antihistamine, which shows anticholinesterase activity and inhibits apoptosis mediated by mitochondria. It is not approved by the FDA or the AEMPS as ChEIs because there are not sufficiently clear trials. In the existing ones, the results are contradictory and, in addition, they are scarce. [36]

An attempt was made to develop a mucoadhesive Huperizine A drug with nanoparticles directed to the brain, intranasally administered for the treatment of $\mathrm{AD}$. At the moment, it has only been tested in mice with satisfactory but not sure results. [36]

Another study also with this same drug investigated the protective effects of Huperizine A against injury induced by iron overload in rat neurons. It was observed how treatment with this drug significantly attenuates the decrease in the viability of neuronal cells induced by iron overload. This beneficial role of Huperizine A can be attributed to its attenuation of oxidative stress and mitochondrial dysfunction, but they are not associated with its acetylcholinesterase inhibitory effect. [37]

After uncomercialization, THA serves as an aid today for the design of new potentially applicable agents for the treatment of $\mathrm{AD}$. One of these compounds, specifically 7methoxy nitrocrine (7-MEOTA), has an interesting profile since it has a suppressed hepatotoxicity, but retains the acetylcholinesterase inhibition properties. [33]

The synthesis of new hybrids of 7-methoxy-trocrine-panisidine and heterodimers of 7-methoxytrucine-memantine was studied, and a biological evaluation and coupling studies were carried out. The new derivatives proved to be nonspecific, effective and non-competitive cholinesterase inhibitors, which can achieve multiple objectives, associated with $\mathrm{AD}$ and, therefore, have a potential clinical impact to slow or block the neurodegenerative process related to this disease. [38, 39]

A study was carried out where the procognitive effect of four inhibitors similar to 7-MEOTA-Donepezil and tacrine analogs $\mathrm{N}$-alkylated, novel and related to tacrine was evaluated. Rats were treated intraperitoneally with the anticholinergic agent 3-quinuclidinyl benzylate (QNB, 2.0 $\mathrm{mg} / \mathrm{kg}$ ), followed 30 minutes later by another injection containing a therapeutic dose of a standard or novel ChEIs. The QNB significantly impacted the performance of the animals in $48 \mathrm{~h}$. The four new acetylcholinesterase inhibitors attenuated the effect of QNB, suggesting that these compounds could be candidates for the treatment of AD. [40]

Another interesting class of acetylcholinesterase inhibitors are the Huprins, designed by fusing two fragments of THA and Huperzine A. The most promising ones are the so-called Huprins $\mathrm{X}$ and Y. [33]

The use of chelators (Deferoxamine (Desferin ${ }^{\circledR}$ ) or Deferiprone (Ferriprox $\left.{ }^{\circledR}\right)$ ) to treat the accumulation of iron ions that exists in the brain and which causes oxidative stress, has not been successful due to toxicity and the inability to address the aggregation of the plates. It has not been observed that galantamine acts on that accumulation, so the hypothesis was raised of combining this drug, an effective anticholinergic agent that acts as an antioxidant, and ApoLf, a protein with a strong binding affinity for iron and ability to absorb the excess in the brain. This strategy has the potential to offer a double neuroprotection and neurotherapeutic interventions for the treatment of $\mathrm{AD}$, which can lead to a novel advance in the treatment of AD. Further experimentation is needed to determine the potential of conjugation, as well as the in vitro, ex vivo and in vivo stability tests of the proteo-alkaloid developed. [41]

The development of active immunization (induction of own antibodies) or passive immunization (external administration of selective antibodies) against $\beta$-amyloid and tau protein is still in the development phase.

Immunotherapy against $\beta$-amyloid uses full-length synthetic $\beta$-amyloid peptides or only one fragment, in order to stimulate B cells to generate specific antibodies for the amyloid sequestration of the brain in the peripheral system. So far, the results are positive in animal models with AD, but the benefits of this strategy in humans are scarce, so it is thought that they may only be effective in very early stages of the disease. As for tau protein, the options under investigation include microtubule stabilizing agents, tau protein kinase inhibitors, tau aggregation inhibitors, active and passive immunotherapies and, more recently, tau acetylation inhibitors. Vaccination directed only at this protein has shown benefits in some studies with mice, but studies in humans are also limited. [42]

There is a study where different hydro alcoholic extracts of Sideritis scardica (known as Greek mountain tea, Lamiaceae) are tested for their potential to counteract the toxicity and aggregation of $\beta$-amyloid, which plays a crucial role in the pathogenesis of AD. The nematode Caenorhabditis elegans is used as a model organism for neurodegenerative diseases, and is chosen in this study, since these models have typically involved the transgenic expression of human proteins associated with the disease. [43] 
The treatment of transgenic strains of the nematode expressing $\beta$-amyloid with the extracts of this plant has resulted in a reduced number of peptide aggregates in the region of the head of the worms and alleviated the toxicity of $\beta$-amyloid, observable through the degree of paralyzed animals.

The use of acupuncture for the treatment of $\mathrm{AD}$ has been increasing in recent years. Meta-analysis was carried out in 2015, where it was demonstrated through six combined clinical trials that acupuncture was better than pharmacological treatment due to the improvement of scores on the MMSE scale. On the other hand, it was also observed that the combined treatment with acupuncture and donepezil was more effective than donepezil alone. Only $0.2 \%$ of patients had adverse reactions related to acupuncture during or after treatment, all described as tolerable and not severe. All this leads to affirm that acupuncture can be effective by itself and, in addition, improve the effect of drugs for the treatment of AD. [44]

On the other hand, authors such as Gu in 2012 showed that the Mediterranean diet (characterized by a greater presence of fish, nuts and vegetables, and a lower intake of red meat) is associated with a lower risk of developing AD. [45]

In addition, the results of a meta-analysis carried out in 2015 showed that subjects with vitamin D deficiency had a $21 \%$ higher risk of developing AD. Vitamin D plays a vital role in calcium homeostasis, skeletal metabolism and the functions of the immune, cardiovascular and reproductive systems. However, more studies are needed to confirm these associations and to evaluate the potential beneficial effects of vitamin $\mathrm{D}$ supplements in the prevention of $\mathrm{AD}$. [46]

Some preliminary studies reported that consumption of coffee or caffeine could be associated with a slight reduction in the risk of dementia or, at least, delaying its onset. [47, 48]

The results of another study, found that the performance of intellectual activity periodically, in addition to having more social, mental and physical stimuli show a better cognitive behavior. [49]

Finally, certain studies suggested that the use of certain drugs may also be involved in the onset of the disease.

In 2009, it was studied that lovastatin and, possibly, other lipid-lowering statins could protect the individual against AD. These could stimulate the protective capacity of Tumor Necrosis Factor (TNF), a key aspect of the brain's immune response. [50]

However, a recent meta-analysis of data carried out in 2016 does not confirm the preliminary work. In this metaanalysis, data are collected from 26,340 patients aged between 40 and 82 years ( $44 \%$ with 70 or more years), all of whom have a history of risk factors for vascular disease. The studies used different statins (simvastatin and pravastatin), during a follow-up of 3 to 5 years. The results indicated that there is consistent evidence that the administration of statins does not prevent cognitive deterioration or dementia. [51]

The use of non-steroidal anti-inflammatory drugs is associated with a reduction in the risk of dementia from any cause.
As for benzodiazepines, there are studies that estimate an increased risk of dementia, while in others there is a reduction, so its effect is still unknown.

Data from the Canadian Study of Health and Aging showed that subjects who had been vaccinated in the past for diphtheria, tetanus, poliomyelitis or influenza had a lower risk of developing AD than the unvaccinated. [2]

\subsection{Statistical Analysis of Current Dispensations of Treatments in Pharmacy Offices}

Finally, in order to complete this work, the dispensation data of two pharmacy offices (Pharmacy I and Pharmacy II) during the year 2017 are provided as a sample or treatment reference in a short population segment.

To reference the data provided, we take into account the total number of specialties, instead of the total number of patients attended. This is due to the impossibility of quantifying with reliable figures the number of people served in a pharmacy office, on the other hand, it is possible to calculate the exact dispensed containers.

In Pharmacy I, the total number of units of pharmaceutical specialties dispensed in that year was 97,754, where 242 were medicines for the treatment of $\mathrm{AD}$, which represents $0.24 \%$ of the total.

In Pharmacy II, of a total of 47,085 specialties dispensed, 153 were drugs for the treatment of $\mathrm{AD}$, which represents $0.32 \%$ of total dispensations.

The following graph reflects the data obtained:

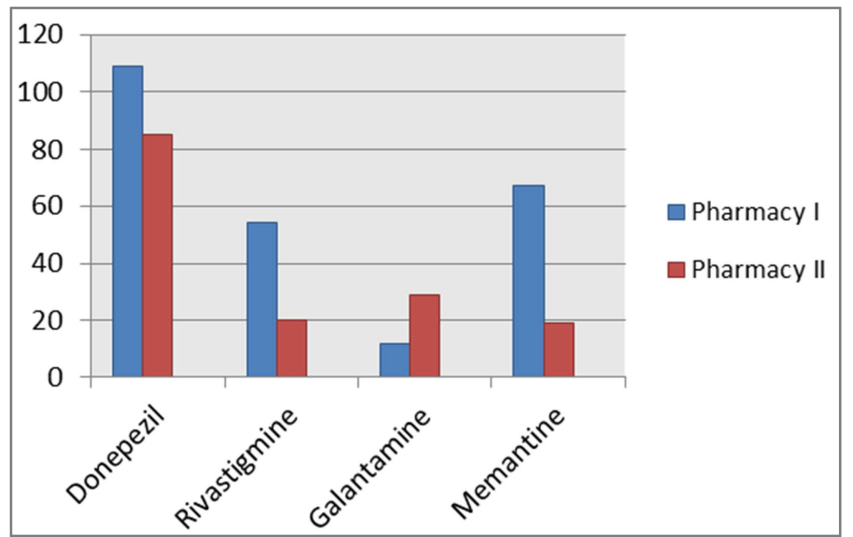

Figure 8. Dispensed units of drugs for the treatment of $A D$ in 2017. Data obtained from Pharmacy I and Pharmacy II.

\section{ANALYSIS OF DISPENSATIONS:}

Breaking down active ingredients, the rotation of each of them in both pharmacies in 2017 was like:

In Pharmacy I, a total of 109 units of donepezil were dispensed, compared to 85 units of Pharmacy II, occupying the first place in sales for the treatment of the $\mathrm{AD}$ in both offices. There is a single pharmaceutical form of this drug which are tablets, normal and dispersible, with two available doses: $5 \mathrm{mg}$ and $10 \mathrm{mg}$.

The specialties for donepezil in these pharmacies are: Aricept ${ }^{\circledR}$, Lixben ${ }^{\circledR}$, Yasnal ${ }^{\circledR}$ and GSP Kern Pharma and Alter. 
The consumption in the last 12 months, broken down by dose, was as follows:

Donepezil 10 mg: 71 units/year Pharmacy I // 35 units/year Pharmacy II.

Donepezil 10 mg FLASH: 12 units/year Pharmacy I // 10 units/year Pharmacy II.

Donepezil 5 mg: 24 units/year Pharmacy I // 15 units/year Pharmacy II.

Donepezil 5 mg FLASH: 2 units/year Pharmacy I // 25 units/year Pharmacy II.

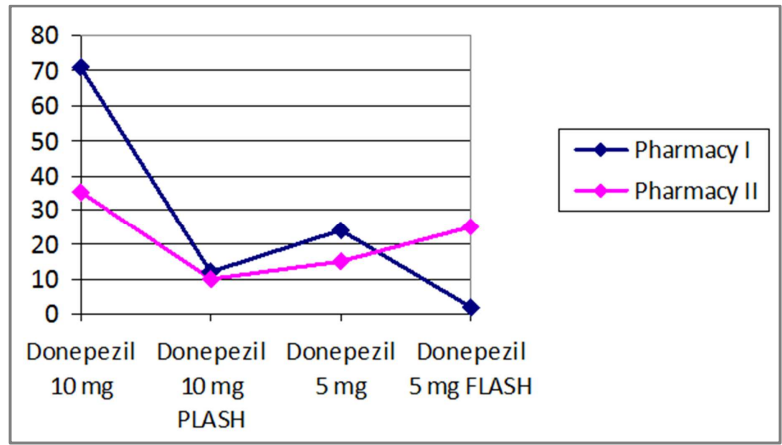

Figure 9. Dispensed units of different specialties of Donepezil in 2017. Data obtained from Pharmacy I and Pharmacy II.

The lowest turnover of specialties of $5 \mathrm{mg}$ compared to 10 $\mathrm{mg}$ is normal, since it is a starting dose, and patients treated with this dose are progressively incorporated to the treatment with the $10 \mathrm{mg}$ dosage. This can be seen clearly in Figure 9.

A total of 54 units of rivastigmine were dispensed in Pharmacy I, compared to Pharmacy II where 20 units were dispensed. There are 3 different dosage forms: capsules, patches and oral suspension, with doses of $1.5 \mathrm{mg}(28,56$ and 112 capsules), $2 \mathrm{mg}$ (120 $\mathrm{ml}$ oral suspension), $3 \mathrm{mg}$ (56 and 112 capsules), $4.5 \mathrm{mg}$ (56 and 112 capsules), $4.6 \mathrm{mg}$ (30 and 60 patches), $6 \mathrm{mg}$ (56 and 112 capsules), $9.5 \mathrm{mg}$ (60 patches) and $12.3 \mathrm{mg}$ (60 patches).

The specialties in these pharmacies were Exelon ${ }^{\circledR}$ Prometax ${ }^{\circledR}$, Demelora ${ }^{\circledR}$ and the Generic Pharmaceutical Specialties (GSP) Kern Pharma, Sandoz, Stada, Aurobindo, Vir and Normon.

On the other hand, 12 units of galantamine were dispensed in Pharmacy I, and 29 units in Pharmacy II. In this case there is only a single pharmaceutical form, capsules, with several doses: $4 \mathrm{mg}, 8 \mathrm{mg}, 16 \mathrm{mg}$ and $24 \mathrm{mg}$, all of 28 capsules

The specialties that are counted in the pharmacies were: Reminyl ${ }^{\circledR}$, Galnora ${ }^{\circledR}$ and GSP Kern Pharma, Normon, Stada, Sandoz and Actavis.

Finally, a total of 67 units of memantine were dispensed in the pharmacy I, and 19 units in the Pharmacy II. There are two doses available: $10 \mathrm{mg}$ (or $10 \mathrm{mg} / \mathrm{ml}$ if it is the oral solution) and $20 \mathrm{mg}$.

In the case of $10 \mathrm{mg}$ presentations, there are two possible pharmaceutical forms: tablets and syrup. The $20 \mathrm{mg}$ presentations are always 56 tablets.

The specialties marketed in this pharmacy are Exura ${ }^{\circledR}$, Ebixa ${ }^{\circledR}$, Mantinex ${ }^{\circledR}$, Marixino ${ }^{\circledR}$ and GSP Alter and Ratiopharm.

As can be seen clearly in Figure 8, the preferred treatment for the disease in this small population segment is donepezil, which confirms the previous results of articles discussed throughout this paper.

In relation to the sales data analyzed, within the ChEIs $22.31 \%$ of the patients of Pharmacy I are being treated with rivastigmine and $13.07 \%$ in Pharmacy II, $4.95 \%$ with galantamine in the Pharmacy I compared to $18.95 \%$ of Pharmacy II, and 45.04\% with donepezil in Pharmacy I and $55.5 \%$ in Pharmacy II. On the other hand, memantine is used in the treatment of the disease of $27.68 \%$ of patients in Pharmacy I and $12.41 \%$ in Pharmacy II.

The choice of donepezil may respond to the fact that it is the one that has been sold the longest and therefore has a greater experience of use, which guarantees better knowledge of adverse reactions and drug interactions, in addition to confirming its greater effectiveness in various studies.

The proportion of total drugs for $\mathrm{AD}$ dispensed is higher in Pharmacy II $(0.32 \%)$ because the population of the neighborhood has an average age higher than Pharmacy I. This same can also justify the greater amount of Galantamine dispensed in Pharmacy II, since being an aged population, they may require a second-choice treatment other than donepezil.

Finally, there are differences in the proportion of memantine (indicated for the most serious phases of the disease) where there is a greater number of units dispensed in Pharmacy I than in Pharmacy II. This can be justified by the different phases in which the patients are. In Pharmacy II, the total number of donepezils at the starting dose $(5 \mathrm{mg})$ dispensed throughout the year is greater than the total number dispensed at Pharmacy I. In addition, fewer memantines were dispensed at the Pharmacy II. We can deduce then that a greater number of patients in this pharmacy are in the early stages of the disease.

In addition, the treatment protocols that are prescribed in each Health Center (each pharmacy belongs to a different one) are different.

\section{Conclusions}

Alzheimer's disease is a pathology widely investigated without knowing, for the time being, its clear causes or the physio pathological mechanisms that produce it. Although there have been important advances in diagnostic methods, at present it is only possible to alleviate the symptoms minimally and slow down the progress of the disease, through both pharmacological and non-pharmacological processes. Despite the difficulties for its early diagnosis and the lack of knowledge surrounding this disease, the investigation of new treatments is progressing positively. In this regard the studies through several research channels are encouraging.

Given the generalized aging of the population in our environment and once the prognosis of this disease is defined, it is possible to think that it is one of the pathologies that will increase the most in the coming years. Therefore, it can be thought that trials of new drugs will be facilitated and both the FDA and the AEMPS will approve new therapies 
that, at least, will improve the quality of life of Alzheimer's patients. The most promising line of research at the moment is perhaps the Huperizine A mucoadhesive. In addition to therapeutic innovations that may present, it develops a novel form of administration (intranasal) that will facilitate the treatment of patients with dysphagia, a common feature in the pathology. Immunotherapy is another pathway that covers multiple fields, and nowadays it offers good results so it will soon be a good alternative to treat AD.

The results of the analysis of dispensations show how donepezil is the preferred treatment of choice, thus confirming the results of the articles reviewed. In addition, it can be observed that there is an increase in $\mathrm{AD}$ in aging segments of the population, demonstrated with the highest number of initial treatments in Pharmacy II.

\section{References}

[1] Kumar A, Tsao JW, Sanidad MDE. Enfermedad de Alzheimer. StatPearls [Internet]. StatPearls Publishing; 2016 May 4 [cited 2018 May 24]; 1-416. Available from: http://cofsegovia.portalfarma.com/Documentos/Portada/108 Alzheimer.pdf.

[2] Sanidad MDE. Guía de práctica clínica sobre la atención integral a las personas con enfermedad de Alzheimer y otras demencias Guía de práctica clínica sobre la atención integral a las personas con enfermedad de Alzheimer y otras demencias. 2011. 1-416 p.

[3] Kumar A, Tsao JW. Alzheimer Disease [Internet]. StatPearls. StatPearls Publishing; 2018 [cited 2018 May 24]. Available from: http://www.ncbi.nlm.nih.gov/pubmed/29763097.

[4] Freire M. ENFERMEDADES DEL SISTEMA NERVIOSO A TRAVÉS DE LAS PREPARACIONES HISTOLÓGICAS Y DIBUJOS DE RAMÓN Y CAJAL. 2015.

[5] Altuna-Azkargorta M, Mendioroz-Iriarte M. Biomarcadores sanguíneos en la enfermedad de Alzheimer. Neurología [Internet]. 2018 May [cited 2018 May 24]; Available from: http://linkinghub.elsevier.com/retrieve/pii/S0213485318300914.

[6] Khan TK. An Algorithm for Preclinical Diagnosis of Alzheimer's Disease. Front Neurosci [Internet]. Frontiers Media SA; 2018 [cited 2018 May 24]; 12: 275. Available from: http://www.ncbi.nlm.nih.gov/pubmed/29760644.

[7] Velazquez R, Ferreira E, Tran A, Turner EC, Belfiore R, Branca $\mathrm{C}$, et al. Acute tau knockdown in the hippocampus of adult mice causes learning and memory deficits. Aging Cell [Internet]. Wiley/Blackwell (10.1111); 2018 May 10 [cited 2018 May 24]; e12775. Available from: http://doi.wiley.com/10.1111/acel.12775.

[8] Quinn JP, Corbett NJ, Kellett KAB, Hooper NM. Tau Proteolysis in the Pathogenesis of Tauopathies: Neurotoxic Fragments and Novel Biomarkers. J Alzheimers Dis [Internet]. IOS Press; 2018 [cited 2018 May 24]; 63 (1): 13-33. Available http://www.ncbi.nlm.nih.gov/pubmed/29630551.

[9] Marsh J, Alifragis P. Synaptic dysfunction in Alzheimer's disease: the effects of amyloid beta on synaptic vesicle dynamics as a novel target for therapeutic intervention. Neural Regen Res [Internet]. Medknow Publications and Media Pvt.
Ltd.; 2018 Apr [cited 2018 May 24]; 13 (4): 616-23. Available from: http://www.ncbi.nlm.nih.gov/pubmed/29722304.

[10] Suidan GL, Singh PK, Patel-Hett S, Chen Z-L, Volfson D, Yamamoto-Imoto $\mathrm{H}$, et al. Abnormal clotting of the intrinsic/contact pathway in Alzheimer disease patients is related to cognitive ability. Blood Adv [Internet]. 2018 May 8 [cited 2018 May 24]; 2 (9): 954-63. Available from: http://www.ncbi.nlm.nih.gov/pubmed/29700007.

[11] Baldeiras I, Santana I, Leitão MJ, Gens H, Pascoal R, TábuasPereira $\mathrm{M}$, et al. Addition of the $\mathrm{A} \beta 42 / 40$ ratio to the cerebrospinal fluid biomarker profile increases the predictive value for underlying Alzheimer's disease dementia in mild cognitive impairment. Alzheimers Res Ther [Internet]. BioMed Central; 2018 Mar 20 [cited 2018 May 24]; 10 (1): $33 . \quad$ Available from: http://www.ncbi.nlm.nih.gov/pubmed/29558986.

[12] Shimizu S, Hirose D, Hatanaka H, Takenoshita N, Kaneko Y, Ogawa Y, et al. Role of Neuroimaging as a Biomarker for Neurodegenerative Diseases. Front Neurol [Internet]. Frontiers Media SA; 2018 [cited 2018 May 24]; 9: 265. Available http://www.ncbi.nlm.nih.gov/pubmed/29720959.

[13] Bateman RJ, Xiong C, Benzinger TLS, Fagan AM, Goate A, Fox NC, et al. Clinical and biomarker changes in dominantly inherited Alzheimer's disease. N Engl J Med [Internet]. NIH Public Access; 2012 Aug 30 [cited 2018 May 24]; 367 (9): 795-804. Available from: http://www.ncbi.nlm.nih.gov/pubmed/22784036.

[14] Taehan Sin'gyŏngkwa Hakhoe Y, 대한 신경과 학회 DL, Hahn S. Journal of the Korean Neurological Association. J Korean Neurol Assoc [Internet]. 1997 Apr 1 [cited 2018 May 24]; $15 \quad$ (2): $300-8 . \quad$ Available from: https://www.koreamed.org/SearchBasic.php?RID=0031JKNA $/ 1997.15 .2 .300 \& D T=1$.

[15] Prescott JW, Guidon A, Doraiswamy PM, Roy Choudhury K, Liu C, Petrella JR, et al. The Alzheimer structural connectome: changes in cortical network topology with increased amyloid plaque burden. Radiology [Internet]. Radiological Society of North America; 2014 Oct [cited 2018 May 24]; 273 (1): 175-84. Available from: http://www.ncbi.nlm.nih.gov/pubmed/24865310.

[16] Hommet C, Mondon K, Camus V, Ribeiro MJ, Beaufils E, Arlicot N, et al. Neuroinflammation and $\beta$ amyloid deposition in Alzheimer's disease: in vivo quantification with molecular imaging. Dement Geriatr Cogn Disord [Internet]. Karger Publishers; 2014 [cited 2018 May 24]; 37 (1-2): 1-18. Available from: http://www.ncbi.nlm.nih.gov/pubmed/24107621.

[17] Johnson KA, Sperling RA, Gidicsin CM, Carmasin JS, Maye JE, Coleman RE, et al. Florbetapir (F18-AV-45) PET to assess amyloid burden in Alzheimer's disease dementia, mild cognitive impairment, and normal aging. Alzheimers Dement [Internet]. NIH Public Access; 2013 Oct [cited 2018 May 24]; 9 (5 Suppl): S72-83. Available from: http://www.ncbi.nlm.nih.gov/pubmed/23375563.

[18] Sohn D, Shpanskaya K, Lucas JE, Petrella JR, Saykin AJ, Tanzi RE, et al. Sex Differences in Cognitive Decline in Subjects with High Likelihood of Mild Cognitive Impairment due to Alzheimer's disease. Sci Rep [Internet]. Nature Publishing Group; 2018 May 10 [cited 2018 May 24]; 8 (1): 7490. Available from: http://www.ncbi.nlm.nih.gov/pubmed/29748598. 
[19] Mosca A, Sperduti S, Pop V, Ciavardelli D, Granzotto A, Punzi M, et al. Influence of APOE and RNF219 on Behavioral and Cognitive Features of Female Patients Affected by Mild Cognitive Impairment or Alzheimer's Disease. Front Aging Neurosci [Internet]. Frontiers Media SA; 2018 [cited 2018 May 24]; 10: 92. Available from: http://www.ncbi.nlm.nih.gov/pubmed/29755337.

[20] Zhong G, Wang Y, Zhang Y, Guo JJ, Zhao Y. Smoking is associated with an increased risk of dementia: a meta-analysis of prospective cohort studies with investigation of potential effect modifiers. PLoS One [Internet]. Public Library of Science; 2015 [cited 2018 May 24]; 10 (3): e0118333. Available http://www.ncbi.nlm.nih.gov/pubmed/25763939.

[21] Iadecola C, Yaffe K, Biller J, Bratzke LC, Faraci FM, Gorelick PB, et al. Impact of Hypertension on Cognitive Function: A Scientific Statement From the American Heart Association. Hypertens (Dallas, Tex 1979) [Internet]. NIH Public Access; 2016 [cited 2018 May 24]; 68 (6): e67-94. Available http://www.ncbi.nlm.nih.gov/pubmed/27977393.

[22] Blake DT, Terry A V, Plagenhoef M, Constantinidis C, Liu R. Potential for intermittent stimulation of nucleus basalis of Meynert to impact treatment of alzheimer's disease. Commun Integr Biol [Internet]. Taylor \& Francis; 2017 [cited 2018 May 24]; $\quad 10 \quad$ (5-6): e1389359. Available from: http://www.ncbi.nlm.nih.gov/pubmed/29260798.

[23] Tratamiento NO Farmacológico - Fundación Azheimer España [Internet]. [cited 2018 May 24]. Available from: http://www.alzfae.org/fundacion/150/tratamiento-nofarmacologico.

[24] Fernandez E, Bergado Rosado JA, Rodriguez Perez D, Salazar Santana S, Torres Aguilar M, Bringas ML. Effectiveness of a Computer-Based Training Program of Attention and Memory in Patients with Acquired Brain Damage. Behav Sci (Basel, Switzerland) [Internet]. Multidisciplinary Digital Publishing Institute (MDPI); 2017 Dec 30 [cited 2018 May 24]; 8 (1). Available http://www.ncbi.nlm.nih.gov/pubmed/29301194.

[25] Tárraga L, Boada M, Modinos G, Espinosa A, Diego S, Morera A, et al. A randomised pilot study to assess the efficacy of an interactive, multimedia tool of cognitive stimulation in Alzheimer's disease. J Neurol Neurosurg Psychiatry [Internet]. BMJ Publishing Group; 2006 Oct [cited 2018 May 24]; 77 (10): 1116-21. Available from: http://www.ncbi.nlm.nih.gov/pubmed/16820420.

[26] Groot C, Hooghiemstra AM, Raijmakers PGHM, van Berckel BNM, Scheltens P, Scherder EJA, et al. The effect of physical activity on cognitive function in patients with dementia: A meta-analysis of randomized control trials. Ageing Res Rev [Internet]. Elsevier; 2016 Jan 1 [cited 2018 May 24]; 25: 1323. Available from: https://www.sciencedirect.com/science/article/pii/S156816371 5300349?via\%3Dihub.

[27] Tratamiento farmacológico actual de la enfermedad de Alzheimer | kNOWAlzheimer [Internet]. [cited 2018 May 24]. Available

https://knowalzheimer.com/profesionales/tratamientofarmacologico-actual-de-la-enfermedad-de-alzheimer/.

[28] Ministerio de Sanidad SS e IAE de M y PS. Donepezilo Ficha técnica [Internet]. 2016. p. 1-9. Available from: https://www.aemps.gob.es/cima/pdfs/es/ft/75250/75250_ft.pd.

[29] Ministerio de Sanidad SS e IAE de M y PS. Ficha técnica: Rivatigmina Kern Pharma [Internet]. 2016. p. 1-16. Available from:

https://www.aemps.gob.es/cima/pdfs/es/ft/77243/77243_ft.pdf.

[30] Ministerio de Sanidad SS e IAE de M y PS. Ficha técnica de Reminyl (galantamina) [Internet]. Ministerio de Sanidad, Política Social e Igualdad. 2013. p. 1-14. Available from: https://www.aemps.gob.es/cima/pdfs/es/ft/66652/FT_66652.p df.

[31] Ministerio de Sanidad SS e IAE de M y PS. Ficha técnica: Memantina Alter [Internet]. 2016. p. 1-8. Available from: https:/www.aemps.gob.es/cima/pdfs/es/ft/77746/77746_ft.pdf.

[32] Knight R, Khondoker M, Magill N, Stewart R, Landau S. A Systematic Review and Meta-Analysis of the Effectiveness of Acetylcholinesterase Inhibitors and Memantine in Treating the Cognitive Symptoms of Dementia. Dement Geriatr Cogn Disord [Internet]. Karger Publishers; 2018 May 7 [cited 2018 May 24]; 45 (3-4): 131-51. Available from: http://www.ncbi.nlm.nih.gov/pubmed/29734182.

[33] Mezeiova E, Korabecny J, Sepsova V, Hrabinova M, Jost P, Muckova L, et al. Development of 2-Methoxyhuprine as Novel Lead for Alzheimer's Disease Therapy. Molecules [Internet]. Multidisciplinary Digital Publishing Institute; 2017 Jul 28 [cited 2018 May 24]; 22 (8): 1265. Available from: http://www.mdpi.com/1420-3049/22/8/1265.

[34] Ma Y, Ji J, Li G, Yang S, Pan S. Effects of donepezil on cognitive functions and the expression level of $\beta$-amyloid in peripheral blood of patients with Alzheimer's disease. Exp Ther Med [Internet]. Spandidos Publications; 2018 Feb [cited 2018 May 24]; 15 (2): 1875-8. Available from: http://www.ncbi.nlm.nih.gov/pubmed/29434777.

[35] Furiya $\mathrm{Y}$, Tomiyama $\mathrm{T}$, Izumi $\mathrm{T}$, Ohba $\mathrm{N}$, Ueno $\mathrm{S}$. Rivastigmine Improves Appetite by Increasing the Plasma Acyl/Des-Acyl Ghrelin Ratio and Cortisol in Alzheimer Disease. Dement Geriatr Cogn Dis Extra [Internet]. Karger Publishers; 2018 [cited 2018 May 24]; 8 (1): 77-84. Available from: http://www.ncbi.nlm.nih.gov/pubmed/29706984.

[36] Meng Q, Wang A, Hua H, Jiang Y, Wang Y, Mu H, et al. Intranasal delivery of Huperzine $A$ to the brain using lactoferrin-conjugated N-trimethylated chitosan surfacemodified PLGA nanoparticles for treatment of Alzheimer's disease. Int J Nanomedicine [Internet]. Dove Press; 2018 [cited 2018 May 24]; 13: 705-18. Available from: http://www.ncbi.nlm.nih.gov/pubmed/29440896.

[37] Tao L-X, Huang X-T, Chen Y-T, Tang X-C, Zhang H-Y. Acetylcholinesterase-independent protective effects of huperzine A against iron overload-induced oxidative damage and aberrant iron metabolism signaling in rat cortical neurons. Acta Pharmacol Sin [Internet]. Nature Publishing Group; 2016 Nov [cited 2018 May 24]; 37 (11): 1391-400. Available from: http://www.ncbi.nlm.nih.gov/pubmed/27498774.

[38] Korabecny J, Andrs M, Nepovimova E, Dolezal R, Babkova K, Horova A, et al. 7-Methoxytacrine-pAnisidine Hybrids as Novel Dual Binding Site Acetylcholinesterase Inhibitors for Alzheimer's Disease Treatment. Molecules [Internet]. Multidisciplinary Digital Publishing Institute; 2015 Dec 10 [cited 2018 May 24]; 20 (12): 22084-101. Available from: http://www.mdpi.com/1420-3049/20/12/19836. 
[39] Gazova Z, Soukup O, Sepsova V, Siposova K, Drtinova L, Jost P, et al. Multi-target-directed therapeutic potential of 7methoxytacrine-adamantylamine heterodimers in the Alzheimer's disease treatment. Biochim Biophys Acta - Mol Basis Dis [Internet]. Elsevier; 2017 Feb 1 [cited 2018 May 24]; 1863 (2): 607-19. Available from: https://www.sciencedirect.com/science/article/pii/S092544391 6303027?via\%3Dihub.

[40] Misik J, Korabecny J, Nepovimova E, Cabelova P, Kassa J. The effects of novel 7-MEOTA-donepezil like hybrids and Nalkylated tacrine analogues in the treatment of quinuclidinyl benzilate-induced behavioural deficits in rats performing the multiple T-maze test. Biomed Pap [Internet]. Biomedical Papers; 2015 Feb 10 [cited 2018 May 24]; 159 (4): 547-53. Available from: http://biomed.papers.upol.cz/doi/10.5507/bp.2015.006.html.

[41] Akilo OD, Kumar P, Choonara YE, Pradeep P, du Toit LC, Pillay V. Hypothesis: apo-lactoferrin-Galantamine Proteoalkaloid Conjugate for Alzheimer's disease Intervention. J Cell Mol Med [Internet]. Wiley-Blackwell; 2018 Mar [cited 2018 May 24]; 22 (3): 1957-63. Available from: http://www.ncbi.nlm.nih.gov/pubmed/29377514.

[42] Wisniewski T, Drummond E. Developing therapeutic vaccines against Alzheimer's disease. Expert Rev Vaccines [Internet]. NIH Public Access; 2016 [cited 2018 May 24]; 15 (3): 40115. Available from: http://www.ncbi.nlm.nih.gov/pubmed/26577574.

[43] Heiner F, Feistel B, Wink M. Sideritis scardica extracts inhibit aggregation and toxicity of amyloid- $\beta$ in Caenorhabditis elegans used as a model for Alzheimer's disease. PeerJ [Internet]. PeerJ, Inc; 2018 [cited 2018 May 24]; 6: e4683. Available http://www.ncbi.nlm.nih.gov/pubmed/29736334.

[44] Zhou J, Peng W, Xu M, Li W, Liu Z. The effectiveness and safety of acupuncture for patients with Alzheimer disease: a systematic review and meta-analysis of randomized controlled trials. Medicine (Baltimore) [Internet]. Wolters Kluwer Health; 2015 Jun [cited 2018 May 24]; 94 (22): e933. Available http://www.ncbi.nlm.nih.gov/pubmed/26039131.

from:

[45] Gardener S, Gu Y, Rainey-Smith SR, Keogh JB, Clifton PM,
Mathieson SL, et al. Adherence to a Mediterranean diet and Alzheimer's disease risk in an Australian population. Transl Psychiatry [Internet]. Nature Publishing Group; 2012 Oct 2 [cited 2018 May 24]; 2 (10): e164. Available from: http://www.ncbi.nlm.nih.gov/pubmed/23032941.

[46] Shen L, Ji H-F. Vitamin D deficiency is associated with increased risk of Alzheimer's disease and dementia: evidence from meta-analysis. Nutr J [Internet]. BioMed Central; 2015 Aug 1 [cited 2018 May 24]; 14: 76. Available from: http://www.ncbi.nlm.nih.gov/pubmed/26231781.

[47] Basurto-Islas G, Blanchard J, Tung YC, Fernandez JR, Voronkov M, Stock M, et al. Therapeutic benefits of a component of coffee in a rat model of Alzheimer's disease. Neurobiol Aging [Internet]. NIH Public Access; 2014 Dec [cited 2018 May 24]; 35 (12): 2701-12. Available from: http://www.ncbi.nlm.nih.gov/pubmed/25034344.

[48] Kwok MK, Leung GM, Schooling CM. Habitual coffee consumption and risk of type 2 diabetes, ischemic heart disease, depression and Alzheimer's disease: a Mendelian randomization study. Sci Rep [Internet]. Nature Publishing Group; 2016 [cited 2018 May 24]; 6: 36500. Available from: http://www.ncbi.nlm.nih.gov/pubmed/27845333.

[49] Taqi MM, Bazov I, Watanabe H, Sheedy D, Harper C, Alkass $\mathrm{K}$, et al. Prodynorphin CpG-SNPs associated with alcohol dependence: elevated methylation in the brain of human alcoholics. Addict Biol [Internet]. NIH Public Access; 2011 Jul [cited 2018 May 24]; 16 (3): 499-509. Available from: http://www.ncbi.nlm.nih.gov/pubmed/21521424.

[50] Kell DB. Iron behaving badly: inappropriate iron chelation as a major contributor to the aetiology of vascular and other progressive inflammatory and degenerative diseases. BMC Med Genomics [Internet]. BioMed Central; 2009 Jan 8 [cited 2018 May 24]; 2: 2. Available from: http://www.ncbi.nlm.nih.gov/pubmed/19133145.

[51] Greenan C, Murphy L, Yu L-M, Kehoe PG, Coulthard E, Bath $\mathrm{P}$, et al. A randomised controlled trial of calcium channel blockade (CCB) with Amlodipine For the treatment of subcortical ischaEmic vasCular demenTia (AFFECT): study protocol. Trials [Internet]. BioMed Central; 2016 [cited 2018 May 24]; 17 (1): 324. Available from: http://www.ncbi.nlm.nih.gov/pubmed/27430267. 